Psychother Psychosom 2019;88:247-248

DOI: $10.1159 / 000501215$

\section{Newer-Generation Antidepressants and Suicide Risk in Randomized Controlled Trials: A Re-Analysis of the FDA Database}

\author{
Michael P. Hengartner $^{\mathrm{a}}$ Martin Plöderl $^{\mathrm{b}}$

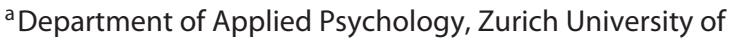 \\ Applied Sciences, Zurich, Switzerland; ${ }^{b}$ Department for Crisis \\ Intervention and Suicide Prevention and Department for Clinical \\ Psychology, University Clinic for Psychiatry, Psychotherapy, and \\ Psychosomatics, Paracelsus Medical University, Salzburg, Austria
}

Dear Editor,

Studies disagree whether antidepressants may trigger suicide attempts in adults with major depression. Some meta-analyses of randomized controlled trials (RCT) found significantly elevated rates of (attempted) suicide in antidepressant arms relative to placebo $[1,2]$, whereas others did not $[3,4]$. A recent study by Khan et al. [5] likewise found no statistically significant differences between antidepressants and placebo, but their study was based on patient exposure years (PEY). This approach has been questioned [6], since the vast majority of (attempted) suicides in RCT occur within the first 3-4 weeks of acute treatment [2]. Patients who do not tolerate the drugs are more likely to terminate trials early due to adverse events [7], for example because of extreme agitation/ akathisia, which may trigger suicide attempts [8]. Populationwide, register-based observational studies confirmed that the suicide risk is highest during the first few weeks after treatment initiation and close to zero thereafter when there is no change in the dosage [9]. Statisticians stressed that PEY must not be applied when hazards (i.e., the risk of adverse events) are not constant over time [10]. Since the constant-hazard requirement for (attempted) suicide is violated in antidepressant trials, PEY may obscure a truly increased suicide risk related to the initiation of antidepressants. Therefore, FDA regulation requires that suicide events are analyzed based on the number of patients randomized to treatment arms, and this is the method the FDA applies in its own evaluations [3].

The aim of this paper was to examine whether the use of newergeneration antidepressants, relative to placebo, bear an increased risk of (attempted) suicide when the analysis is based on the number of patients instead of PEY.

We re-analyzed the data presented in Table 1 of Khan et al. [5]. These were based on the integrated safety summaries provided by the FDA for all phase II and III trials conducted by the pharmaceutical industry as part of new drug approval programs for adults (>18 years) with major depression. The sample comprised the fol- lowing drugs approved between 1991 and 2013: sertraline, paroxetine, venlafaxine, nefazodone, mirtazapine, venlafaxine ER, citalopram, escitalopram, duloxetine, desvenlafaxine, trazodone ER, vilazodone, levomilnacipram, and vortioxetine. Contrary to Khan et al. [5], we did not count the one suicide in a vilazodone trial, as this event occurred prior to the first treatment application. Finally, as Khan et al. [5] did not report the number of patients randomized to placebo in the levomilnacipran program, it was taken from the FDA approval summary review.

We used the statistic software R and the package "epitools" to compute the odds ratio (OR) and the number needed to harm (NNH) for antidepressants versus placebo based on $2 \times 2$ contingency tables and applying two-tailed mid- $p$ values. In addition, we calculated Bayes factors (BF) with the package "BayesFactor" to quantify how much the data support a true effect (alternative hypothesis H1) against a null effect (null hypothesis $\mathrm{H} 0$ ). For the Bayesian analysis, we fitted independent multinomial models with columns fixed and 500,000 resamples. Per convention, the strength of evidence for $\mathrm{H} 1$ against $\mathrm{H} 0$ is interpreted as follows: $\mathrm{BF}=1-3$ : weak; $\mathrm{BF}=3-20$ : positive; $\mathrm{BF}=20-150$ : strong; and $\mathrm{BF}>150$ : very strong.

The number of suicide events stratified by drug is shown in Table 1 . There were 37 suicides $(0.116 \%)$ and 206 suicide attempts $(0.713 \%)$ in antidepressant arms versus 4 suicides $(0.040 \%)$ and 28 suicide attempts $(0.300 \%)$ in placebo arms. The suicide rate was higher in the antidepressant than in the placebo group $(\mathrm{OR}=2.83$, $95 \% \mathrm{CI}=1.13-9.67, p=0.02, \mathrm{BF}=$ n.a.). Unfortunately, the weak evidence in combination with an uninformative prior distribution leads to Lindley's paradox, which made the BF uninterpretable. The absolute risk increase was $0.077 \%$ or about 77 suicides per 100,000 antidepressant users, corresponding to a NNH of 1,303. The suicide attempt rate was increased in antidepressant arms relative to placebo $(\mathrm{OR}=2.38,95 \% \mathrm{CI}=1.63-3.61, p<0.00001$, $\mathrm{BF}=180.1$ [very strong evidence]). The absolute risk increase was $0.413 \%$ or about 413 suicide attempts per 100,000 antidepressant users. The corresponding $\mathrm{NNH}$ was 242 . The rate of suicides and suicide attempts combined (based on programs that reported both events) was significantly higher in antidepressant arms relative to placebo $(\mathrm{OR}=2.49,95 \% \mathrm{CI}=1.74-3.70, p<0.00001, \mathrm{BF}=3543.0$ [very strong evidence]). The $\mathrm{NNH}$ was 202 , and the absolute risk increase was $0.495 \%$; thus, the number of excess suicides and suicide attempts combined would be about 495 per 100,000 antidepressant users.

As part of a sensitivity analysis, we added data from the fluoxetine and bupropion programs (approved in 1987 and 1996) as reported by Healy and Whitaker [2]. In the bupropion program, there were 3 suicides in the active treatment arm $(n=1,942)$ and none in the placebo arm $(n=370)$. Data on suicide attempts were not available. In the fluoxetine program, there were 1 suicide and 12 suicide attempts in the active treatment arm $(n=1,427)$, and no events in the placebo arm $(n=370)$. Including these data did not

\section{KARGER}

E-Mail karger@karger.com www.karger.com/pps
(C) 2019 The Author(s)

Published by S. Karger AG, Basel

Karger

Open access

This article is licensed under the Creative Commons AttributionNonCommercial-NoDerivatives 4.0 International License (CC BYNC-ND) (http://www.karger.com/Services/OpenAccessLicense). Usage and distribution for commercial purposes as well as any distribution of modified material requires written permission.
Michael P. Hengartner, PhD

Senior Research Fellow and Lecturer, Department of Applied Psychology

Zurich University of Applied Sciences (ZHAW), PO Box 707

CH-8037 Zurich (Switzerland)

E-Mail michaelpascal.hengartner@zhaw.ch 
Table 1. Number of suicides and suicide attempts in 14 investigational antidepressants approved by the FDA between 1991 and 2013

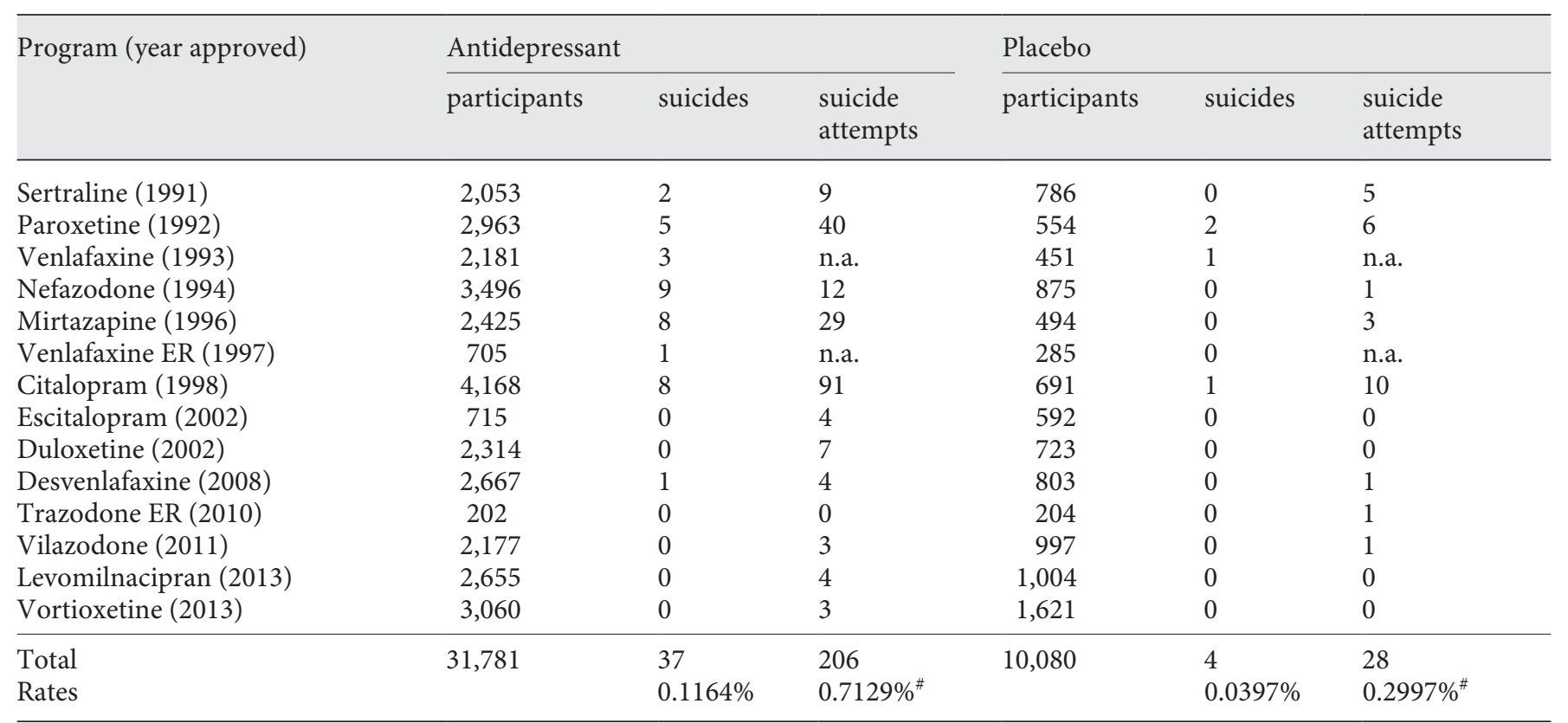

Following Khan et al. [5], fluoxetine and bupropion trials were excluded from the main analysis due to lack of pertinent data on PEY, but we included them in a sensitivity analysis (see main text). n.a., numbers were not available because suicide attempts were reported together with events of suicidal ideation. ${ }^{*}$ Excluding venlafaxine and venlafaxine ER samples, where suicide attempt data was not available.

alter the results appreciably for suicides $(\mathrm{OR}=3.05,95 \% \mathrm{CI}=1.23-$ $10.36, p=0.01, \mathrm{BF}=\mathrm{n} . \mathrm{a}$.$) , suicide attempts (\mathrm{OR}=2.49,95 \% \mathrm{CI}=$ $1.71-3.78, p<0.00001, \mathrm{BF}=844.0$ [very strong evidence]), and for suicides and suicide attempts combined $(\mathrm{OR}=2.61,95 \% \mathrm{CI}=$ $1.82-3.86, p<0.00001, \mathrm{BF}=20152.5$ [very strong evidence]).

In this re-analysis of the FDA safety summaries, we found evidence that the rate of (attempted) suicide was about 2.5 times higher in antidepressant arms relative to placebo. Our findings thus conflict with the work by Khan et al. [5], who based their effect estimates on PEY rather than the number of patients. When hazards are not constant over time, PEY is inappropriate [10] and may obscure a true adverse drug effect, since (attempted) suicide mostly occurs shortly after treatment initiation and not during continuation or maintenance phases [6,9]. Adverse-event risk should therefore be calculated based on the number of patients exposed to treatments rather than PEY, and this is also the approach applied by the FDA [3]. Thus, when based on the number of patients randomized rather than $\mathrm{PEY}$, the data presented herein suggest that antidepressants significantly increase the suicide risk in adults with major depression. Further research is required to establish whether the increased suicide risk observed in RCT generalizes to real-world practice, and we acknowledge that suicide attempts constitute just one aspect of a thorough risk-benefit evaluation.

Disclosure Statement

Both authors declare no conflicts of interests.

Funding Sources

No funding was received for this work.

\section{References}

1 Fergusson D, Doucette S, Glass KC, Shapiro S, Healy D, Hebert P, et al. Association between suicide attempts and selective serotonin reuptake inhibitors: systematic review of randomised controlled trials. BMJ. 2005 Feb;330(7488):396.

2 Healy D, Whitaker C. Antidepressants and suicide: risk-benefit conundrums. J Psychiatry Neurosci. 2003 Sep;28(5):331-7.

3 Stone M, Laughren T, Jones ML, Levenson M, Holland PC, Hughes A, et al. Risk of suicidality in clinical trials of antidepressants in adults: analysis of proprietary data submitted to US Food and Drug Administration. BMJ. 2009 Aug;339 aug11 2:b2880.

4 Sharma T, Guski LS, Freund N, Gøtzsche PC. Suicidality and aggression during antidepressant treatment: systematic review and meta-analyses based on clinical study reports. BMJ. 2016 Jan;352:i65.

5 Khan A, Fahl Mar K, Gokul S, Brown WA. Decreased suicide rates in recent antidepressant clinical trials. Psychopharmacology (Berl). 2018 May;235(5):1455-62.

6 Healy D. Did regulators fail over selective serotonin reuptake inhibitors? BMJ. 2006 Jul;333(7558):92-5.

7 Cipriani A, Furukawa TA, Salanti G, Chaimani A, Atkinson LZ, Ogawa $\mathrm{Y}$, et al. Comparative efficacy and acceptability of 21 antidepressant drugs for the acute treatment of adults with major depressive disorder: a systematic review and network meta-analysis. Lancet. 2018 Apr; 391(10128):1357-66.

8 Breggin PR. Suicidality, violence and mania caused by selective serotonin reuptake inhibitors (SSRIs): A review and analysis. Int J Risk Saf Med. 2004; 16:31-49.

9 Valuck RJ, Orton HD, Libby AM. Antidepressant discontinuation and risk of suicide attempt: a retrospective, nested case-control study. J Clin Psychiatry. 2009 Aug;70(8):1069-77.

10 Kraemer HC. Events per person-time (incidence rate): a misleading statistic? Stat Med. 2009 Mar;28(6):1028-39. 